\title{
ENABLING OR ENFEEBLING THE PRIVATE SECTOR? Government Policy Responses and Business Initiatives during COVID-19
}

\author{
Gracie Rosenbach and Danielle Resnick
}

\begin{abstract}
he economic effects of the COVID-19 pandemic - at the global, country, and household levels - are dramatic, plunging the world into a recession not experienced in more than a half century (World Bank 2020a). Unlike other recent global crises, such as the food price crisis (2007-2008) or the financial crisis (2008), the pandemic has affected businesses across all industries and sectors, from agriculture to manufacturing to tourism, services, and mining. At the same time, it is spurring new innovations in response to public health needs and technological advances. This policy brief uses data from the COVID-19 Policy Response (CPR) Portal to examine trends in how government COVID-19 response policies have hindered or promoted the private sector, as well as the private sector's role in combatting the pandemic. Comparing these policies and responses can provide useful insights into best practices for balancing the twin goals of economic and public health during a crisis.
\end{abstract}

\section{PROTECTING THE POPULATION AT THE COST OF THE PRIVATE SECTOR}

To combat the spread of COVID-19, many countries instituted "lockdown policies" in which non-essential businesses had to temporarily close and the population was required to remain at home except for essential reasons. Following an initial four- to eight-week lockdown period, many countries took a gradual approach to reopening of non-essential private sector activities. In many instances, markets, restaurants, manufacturing, and transportation were some of the first businesses to resume. Among the last to reopen have been sports, gyms, bars, theaters, and shopping malls. While often credited with successfully curbing significant community spread of COVID-19 in many countries, these policies have severely and negatively impacted many businesses, forcing them to close down completely or to lay off staff (Hsiang et al. 2020).

Additionally, to promote people's welfare, governments established many food and non-food price controls because of fears that businesses would engage in price gouging for essential items. Governments chose to regulate a range of food and non-food products, as seen in Table 1. It is not clear how price ceilings were determined, or if they involved any dialogue with businesses that produce these products.

In addition to government-imposed price ceilings, government-mandated protections for employees may have had harmful effects on businesses even as they cushioned the livelihoods of workers. In India and Sri Lanka, certain companies were required to continue paying wages regardless of a worker's ability to perform his or her duties due to COVID-19, and regardless of whether the company was able to operate during the lockdown. Similarly, in Ethiopia, Mozambique, and Senegal, businesses were not allowed to lay off employees regardless of a company's ability to operate.

\section{TRADE POLICIES PRIORITIZE PROTECTING DOMESTIC BUSINESSES AND THE LOCAL POPULATION}

The main trade policy trends reported in the CPR suggest that during the pandemic, governments have sought to benefit domestic businesses and the local economy by promoting the export of specific products, while also ensuring the health and safety of their citizens by waiving certain import taxes and banning the export of essential items (Figure 1). Policies to promote local economies mainly focus on highvalue exports: for example, Ethiopia removed the minimum price for flower exports, Uzbekistan is providing a transportation subsidy for exporting horticultural products, textiles, and other products, and Zambia suspended the export duties on crocodile skins and precious metals. In Bangladesh, the government waived the import tax on aquaculture and livestock feeds to support the agricultural sector.

However, most of the COVID-19-related trade policies aim to ensure the health and food security of the population, and ultimately may have mixed effects on local economies. Many countries waived or reduced import taxes on 
TABLE 1 Distribution of Food and Non-Food Price Ceilings

\begin{tabular}{|c|c|c|c|c|c|}
\hline \multirow[b]{2}{*}{ COUNTRY } & \multicolumn{2}{|c|}{ FOOD } & \multicolumn{3}{|c|}{ NON-FOOD } \\
\hline & $\begin{array}{l}\text { Staple } \\
\text { foods }\end{array}$ & $\begin{array}{l}\text { Food } \\
\text { basket }\end{array}$ & $\begin{array}{l}\text { Health/ } \\
\text { hygiene }\end{array}$ & $\begin{array}{c}\text { Fuel/ } \\
\text { transpor- } \\
\text { tation }\end{array}$ & $\begin{array}{c}\text { Other } \\
\text { essential } \\
\text { items/ } \\
\text { services }\end{array}$ \\
\hline Burkina Faso & & & & & \\
\hline Egypt & & & & & \\
\hline Ethiopia & & & & & \\
\hline Honduras & & & & & \\
\hline Kazakhstan & & & & & \\
\hline Malawi & & & & & \\
\hline Mali & & & & & \\
\hline Mozambique & & & & & \\
\hline Nigeria & & & & & \\
\hline Pakistan & & & & & \\
\hline $\begin{array}{r}\text { Papua New } \\
\text { Guinea }\end{array}$ & & & & & \\
\hline Rwanda & & & & & \\
\hline Senegal & & & & & \\
\hline Sri Lanka & & & & & \\
\hline Tajikistan & & & & & \\
\hline Timor Leste & & & & & \\
\hline Uzbekistan & & & & & \\
\hline
\end{tabular}

Source: IFPRI (2020)

Note: Information is based on data collected up to October 16, 2020. The countries listed here are only those with price ceilings and do not represent the full list of countries in the CPR database. health supplies, staple foods, and other essential goods. Some governments further promoted imports of these items through additional policies. For example, Ethiopia advertised that the government was collecting bids from international companies to import large amounts of wheat, rice, sugar, and edible oils tax free; Ghana suspended the rent charges for cargo during the lockdown; Mali increased the storage available at border points for imports of essential items; and Myanmar relaxed the licensing requirements for imports of medical supplies. Finally, to ensure enough essential food and medical items for the population, most countries also enacted export bans on such items - Egypt and Honduras banned export of many legumes; Sudan banned export of sorghum; India, Kenya, Mali, Pakistan, Russia, and Uzbekistan banned export of certain health products; and Kazakhstan, Kyrgyzstan, Mali, Pakistan, and Tajikistan banned export of numerous food items to promote food and nutrition security.

\section{IMPROVING THE RESILIENCE OF THE PRIVATE SECTOR}

At the same time, nearly every country in the CPR Portal also enacted policies to help failing businesses survive and to avoid mass unemployment (Figure 2). The vast majority of countries created programs to provide funds directly to businesses - most of these programs focused specifically on small and medium enterprises (SMEs), often with a secondary focus as well, such as tourism and hospitality (Egypt,

FIGURE 1 Commodities impacted by COVID-19 related trade policies, by policy type

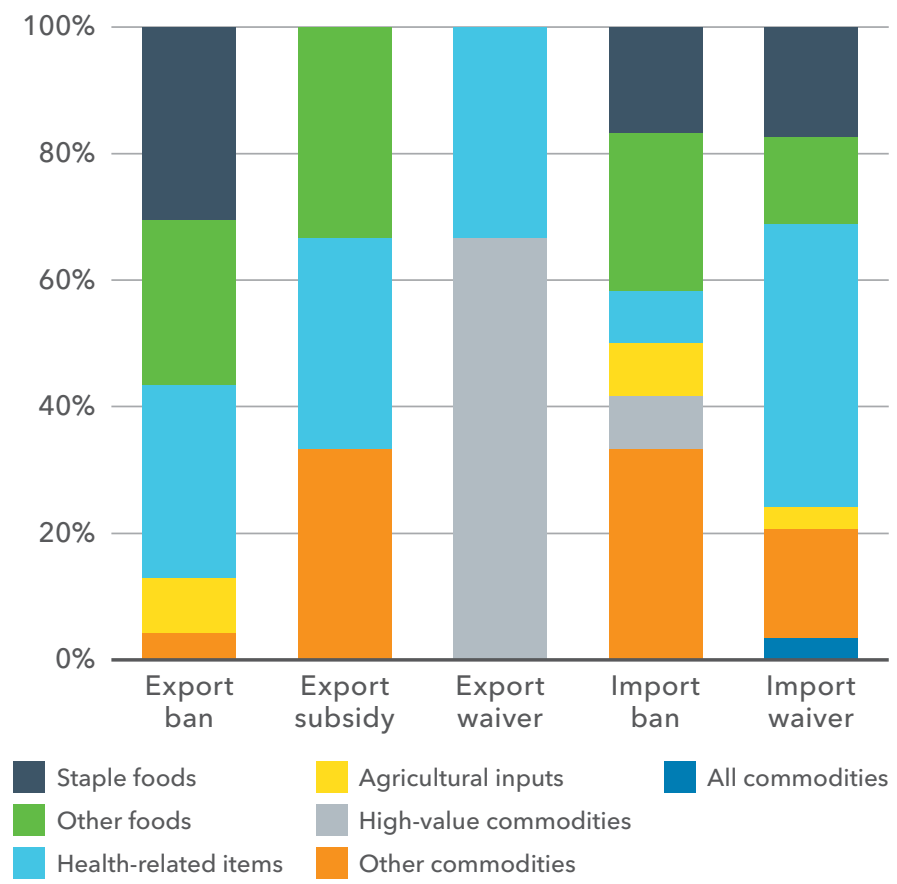

Source: IFPRI (2020).

Note: Information is based on data collected up to October 16, 2020 and refers only to the 33 countries in the CPR database. 
Myanmar, and Uzbekistan), microfinance (Mali), exports (Bangladesh and Egypt), and essential items (Kyrgyzstan, Kenya, and Tajikistan). When comparing the funding commitments by governments for private sector promotion, these funds, which are disbursed either through grants or loans, enjoyed significantly higher commitments than the other policy levers. Two countries took a different approach to providing financial support to businesses through public procurement - Kenya allocated US\$5.4 million (600 million shillings) to purchase locally manufactured vehicles through the "Buy Kenya Build Kenya" policy, and Zambia released US\$6.9 million (140 million kwacha) to pay local contractors in the road sector.

Most countries also took measures to waive, reduce, or defer tax and loan payments in order to boost the profitability of businesses. Policies to waive value-added taxes (VAT) were the most common, with 13 countries in the CPR enacting 22 such policies. Some governments passed policies aimed at encouraging banks to expand credit access to the private sector by increasing credit limits (Egypt and Tunisia), guaranteeing loans (Ghana, India, Myanmar), and setting a lower interest rate (Sri Lanka). Governments also supported workers through wage support. The governments of China, Pakistan, and Timor Leste subsidized wages to keep workers employed and earning a decent wage. Finally, in 9 countries in the CPR, most of which are classified as lower-middle or upper-middle income, governments either instituted or increased unemployment benefits (World Bank 2020b).
Many governments sought to stimulate the private sector and keep the economy running by harnessing technological solutions that reduce the need for face-to-face interactions. A key trend evident from the CPR was that nearly all of the African countries eliminated or reduced fees for information and communications technologies (ICT). Additional ICT innovations included the development of e-commerce platforms for easier provision of goods. The Ministry of Trade in Senegal was one of the first government bodies to create such a platform when it launched an online marketplace for the population to buy bread (Kennedy and Resnick 2020). It later expanded this marketplace to include many other essential items so that people could reduce their potential exposure to COVID-19 and businesses could continue to operate. Uganda and India have similar e-commerce platforms that both the general population and the government can use to procure goods and services. Rather than promoting domestic online procurement, Sri Lanka's Export Development Board launched a digital export promotion program as its way of promoting local businesses.

\section{PRIVATE SECTOR CONTRIBUTIONS TO THE FIGHT AGAINST COVID-19}

Business leaders know that adaptability is crucial to profitability, and the COVID-19 pandemic is no exception. Many companies quickly shifted their local production to items necessary to prevent and treat COVID-19, sometimes with support from government incentives. Masks are one of the most

FIGURE 2 Number of government policies to promote the private sector, by policy type and target sector

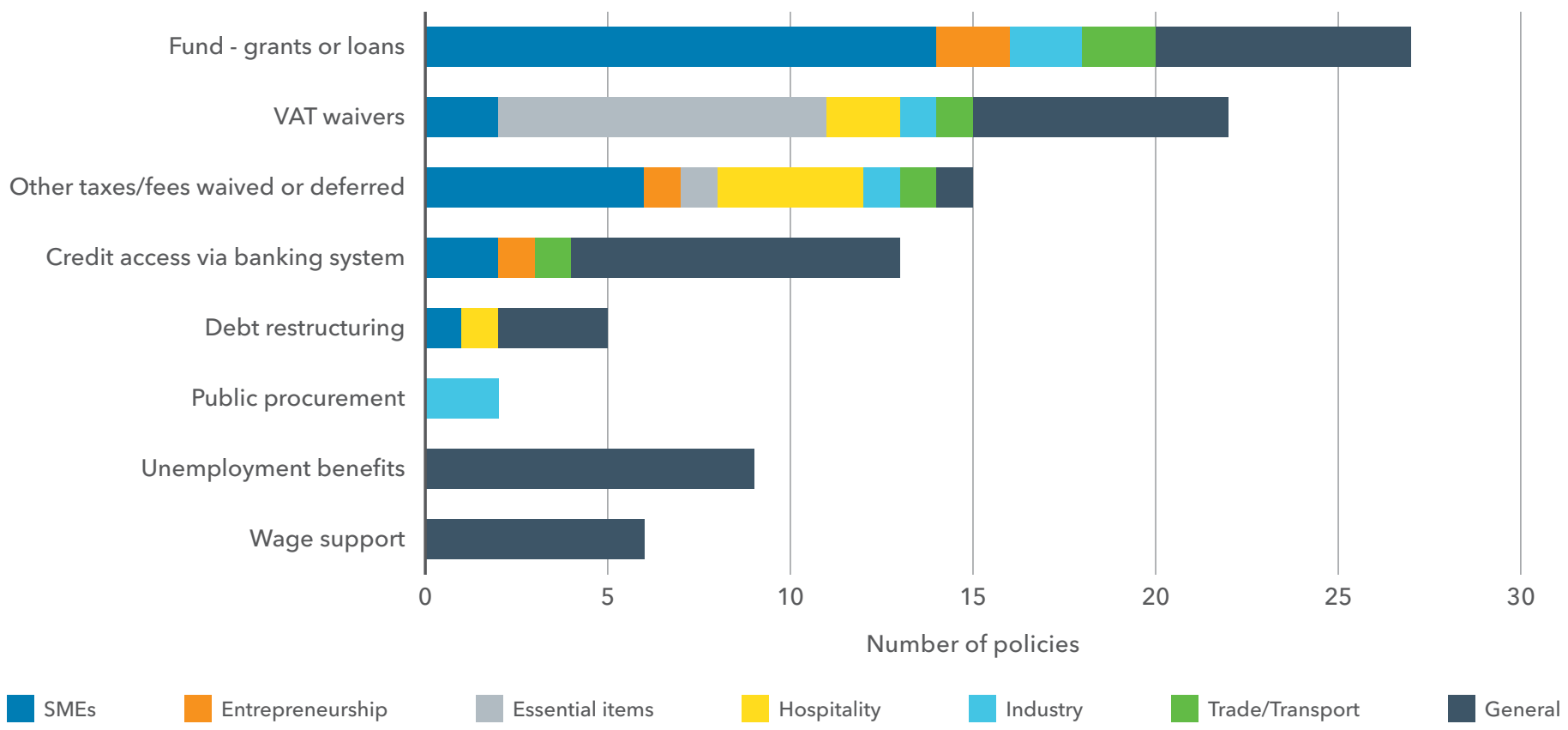

Source: IFPRI (2020)

Note: VAT=value-added taxes; SMEs=small and medium enterprises. Information is based on data collected up to October 16,2020 and refers only to the 33 countries in the CPR database. 
common items being produced locally in many countries, with some companies even leading coalitions and campaigns such as the "Mask for All" campaign initiated by local garment manufacturers in Rwanda, which seeks to provide free facemasks to vulnerable families countrywide. Some businesses switched their production to other types of personal protective equipment (PPE) and related items, such as a new hand-sanitizer factory in Ethiopia and the many local factories in Ghana producing surgical scrubs and gowns. Many countries are even promoting local production of ventilators - Nigeria, Pakistan, and Uzbekistan are working to ramp up production, while the Kenya Association of Manufacturers Automotive Sector set a goal of producing 100 ventilators daily.

On top of selling local products to governments or consumers, many international and local businesses are also making monetary and in-kind donations to governments or local communities. A large range of international companies have donated financially or in-kind to many of the countries in the CPR, including Huawei, Humanwell Pharmaceuticals, Apple, Tiktok, and Anglogold. Among local businesses, PPE and medical supplies are some of the most common donations. For example, Stanbic Bank of Kenya and its partners donated ventilators, Cervejas de Moçambique provided face visors, and Standard Bank Malawi donated other PPE such as suits, gloves, masks, thermometers, and disinfectant gel. The most common private sector donors are banks, extractive industries, and telecommunications. Other companies took a different approach, such as Konga in Nigeria, which reduced fees for certain products to benefit consumers, and MTN, which repurposed its advertising budget across all of the countries where it operates for the month of September to launch the "Wear It For Me" campaign on COVID-19 prevention strategies.

\section{CONCLUSIONS}

As governments around the world seek to balance economic and public health, they have pursued a complex mix of policies to balance the needs of businesses and consumers. Some of these policies benefit the private sector, such as SME funds, subsidized wage payments, and export promotion. But other policies focus more on supporting employees and consumers, potentially at the cost of businesses, such as price controls, import bans, and prohibiting employee layoffs. Despite difficult economic conditions, some companies were able to quickly adapt and also embraced social responsibility to contribute to the fight against COVID-19. Many smaller, more local businesses shifted their production when possible to the manufacturing of health supplies and PPE, while larger companies such as banks, telecommunications, and extractive industries contributed by donating health supplies or launching health campaigns. In these ways, businesses are realizing broader goals in addition to profit maximization by playing a transformative role in the local community and encouraging certain citizen attitudes and behaviors, including following science-based health guidelines. While the lockdowns that hurt the economies and prompted these policy responses are credited with saving many lives and avoiding overwhelmed health systems, the economic effects of the lockdowns and subsequent private sector policies will continue for years to come.

\section{REFERENCES}

Hsiang, S., D. Allen, S. Annan-Phan, K. Bell, I. Bolliger, T. Chong, H. Druckenmiller, L. Huang, A. Hultgren, E. Krasovich, P. Lau, J. Lee, E. Rolf, J. Tseng, and T. Wu. 2020. “The Effect of Large-Scale Anti-Contagion Policies on the COVID-19 Pandemic." Nature 584: 262-267.

International Food Policy Research Institute (IFPRI). 2020. COVID-19 Policy Response (CPR) Portal. https://www.ifpri.org/project/covid-19-policy-response-cpr-portal.

Kennedy, A., and D. Resnick. 2020. "From Farm to Table: How are Governments Keeping Food Systems Functioning during COVID-19?" COVID-19 Policy Response Portal Project Note 1. Washington, DC: International Food Policy Research Institute.

World Bank. 2020a. "COVID-19 to Plunge Global Economy into Worst Recession since World War II." Press release, June 8. https://www.worldbank.org/en/news/pressrelease/2020/06/08/covid-19-to-plunge-global-economy-into-worst-recession-since-world-war-ii.

World Bank. 2020b. World Bank Country and Lending Groups. Accessed October 14. https://datahelpdesk.worldbank.org/knowledgebase/ articles/906519-world-bank-country-and-lending-groups.

The COVID-19 Policy Response Portal (CPR) is managed by the International Food Policy Research Institute (IFPRI) and is financially supported by USAID and the CGIAR Research Program on Policies, Institutions, and Markets (PIM). This publication has been prepared as an output of the CPR. Contributing partners to the CPR include Michigan State University's Food Security Group, Global Alliance for Improved Nutrition (GAIN), Indaba Agricultural Research Institute (IAPRI) of Zambia, Tegemeo Institute

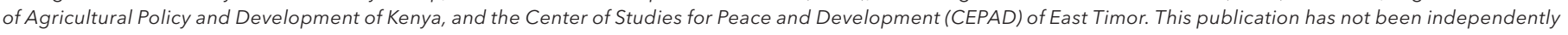
peer reviewed. Any opinions expressed here belong to the author(s) and are not necessarily representative of or endorsed by IFPRI.

INTERNATIONAL FOOD POLICY RESEARCH INSTITUTE

A world free of hunger and malnutrition

IFPRI is a CGIAR Research Center 